
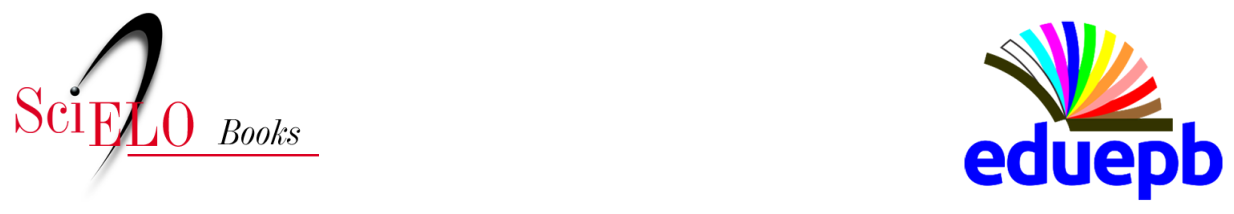

\title{
A Interação em Ambiente Virtual de Aprendizagem: um estudo de caso
}

\author{
Aline Tavares Costa
}

Filomena Maria Gonçalves da Silva Cordeiro Moita

\section{SciELO Books / SciELO Livros / SciELO Libros}

COSTA, A. T., and MOITA, F. M. G. S. C. A Interação em Ambiente Virtual de Aprendizagem: um estudo de caso. In: ARANHA, S. D. G., and SOUZA, F. M., eds. Práticas de ensino e tecnologias digitais [online]. Campina Grande: EDUEPB, 2018, pp. 239-275. Ensino e aprendizagem collection, vol. 3. ISBN: 978-85-78795-26-9. http://doi.org/10.7476/9786586221657.0010.

\section{(c) $\underset{\mathrm{EY}}{(\mathrm{i})}$}

All the contents of this work, except where otherwise noted, is licensed under a Creative Commons Attribution 4.0 International license.

Todo o conteúdo deste trabalho, exceto quando houver ressalva, é publicado sob a licença Creative Commons Atribição 4.0.

Todo el contenido de esta obra, excepto donde se indique lo contrario, está bajo licencia de la licencia Creative Commons Reconocimento 4.0. 


\title{
A INTERAÇÃO EM AMBIENTE VIRTUAL DE APRENDIZAGEM: um estudo de caso
}

\author{
Aline Tavares Costa ${ }^{1}$ \\ Filomena Maria Gonçalves da Silva Cordeiro Moita ${ }^{2}$
}

\section{Introdução}

A instituição escolar oferece, em seu rol de objetivos voltados a formação de um cidadão consciente e ativo em comunidade, a perpetuação dos conhecimentos até então documentados, reunindo etapas e processos sistematizados, que abrigam diversos artefatos tecnológicos. A comunicação, neste ambiente, ocorre em diversas vias, e utiliza, também, diversas tecnologias, evidenciando a complexidade do sistema.

Estando a sociedade atual em um estágio avançado de desenvolvimento digital, tornando suas atividades em processos automatizados, é preciso que existam

1 Mestre em Formação de Professores. Professora substituta do Departamento de Computação da Universidade Estadual da Paraíba - UEPB. Tutora virtual do curso de Licenciatura em Computação, da Universidade Federal Rural de Pernambuco - UFRPE.

2 Doutora em Educação Comunicação e Cultura. Docente do quadro permanente do Programas de Pós-Graduação em Formação de Professores e Ensino de Ciências e Educação Matemática da Universidade Estadual da Paraíba - UEPB. 
indivíduos preparados para, não só utilizar adequadamente cada solução, como também criar novas. As gerações nascidas durante as várias revoluções tecnológicas (fogo, papel, imprensa, internet etc.) possuem características próprias, que facilitam a adaptação aos novos processos, mas que, por outro lado, podem dificultar as relações com os grupos nascidos em outros momentos.

Possíveis entraves podem ser encontrados na mais básica forma de comunicação - a oral. Por muito tempo, essa foi a única forma de interação, e, a todo instante, agrega novos vocábulos das tribos, podendo dificultar a compreensão, inclusive entre seus próprios membros. A escrita também herdou este fenômeno, assim como as tecnologias posteriores, que passaram a criar seus próprios códigos.

A internet, como meio interativo, global e eletrônico, permitiu a congruência desses códigos e o livre acesso a qualquer grupo que se interessasse, o que melhora e acentua a complexidade das novas linguagens. Os recursos digitais também influenciam, pois permitem a utilização de formatos e suportes informacionais específicos, como imagens, vídeos, áudio, emoticons etc.

Para os órgãos padronizadores de processos, como a escola, esta situação pode ser vista como caótica. No entanto, os grupos envolvidos criam no caos a sua própria ordem, ao manipular diversas informações simultaneamente, habilidade muitas vezes podada pela fala do professor. Os alunos, então, encontram liberdade para expressar-se a partir dos recursos digitais online, como nas redes sociais e nos games.

Neste cenário, tem-se buscado formas de aproximar esses dois mundos, com cursos de atualização sobre 
novas tecnologias e dinâmicas pedagógicas, por exemplo, para capacitar os educadores a encontrar formas de envolver o aluno. Um exemplo disso foi o curso de Pós-Graduação Latu Senso "Fundamentos da Educação: Práticas Pedagógicas Interdisciplinares", promovido pelo Governo do Estado da Paraíba, em parceria com a Universidade Estadual da Paraíba, entre 2013 e início de 2015, que se mostrou um espaço de discussão sobre pluralidade cultural, cidadania, tecnologias educacionais etc. Algumas disciplinas foram ministradas online, pelo Moodle, configurando o curso como b-learning, ou seja, com aprendizagem mista, híbrida, pois faz uso de ferramentas online, em parceria com ensino presencial.

A educação online permite o compartilhamento de saberes entre pessoas de localidades fisicamente distantes, portanto culturalmente distintas, provendo, inclusive, o retorno de muitos aos estudos. Docentes, neste novo ambiente, vestem-se de outras práticas, guiam o aluno por atividades em processos de construção de sentidos. Os jovens já descobriram as potencialidades desses recursos, interagem e são produtores de conhecimento, sendo necessário que os educadores orientem a produção, em busca do máximo aproveitamento.

Com este cenário, o presente trabalho objetiva expor um estudo de caso sobre a interação em ambiente virtual de aprendizagem, num curso na modalidade b-learning, que levou em consideração a linguagem utilizada na interação professor-aluno. Para tal, foram observados os diálogos de dois fóruns do módulo de Comunicação e Linguagem, a fim de analisar como o professor mediador e os professores-alunos fazem uso da linguagem para se expressar neste ambiente. 


\section{Interação b-learning na escola}

A voz foi uma das primeiras tecnologias utilizadas pelo homem em suas relações, que, destituídas de qualquer sistematização de métodos e processos, ocorriam de forma natural e instintiva. Com o desenvolvimento de outras tecnologias, formas diversas de interação foram sendo integradas, caracterizando momentos de revolução. No caso da linguagem, essas revoluções são tidas como vagarosas e sutis (CRYSTAL, 2005), pois precisam firmar presença nas práticas sociais de uma comunidade, adequando-se para servir às necessidades de comunicação que possam surgir (SHEPHERD e SALIÉS, 2013). Por outro lado, atualmente, o nascimento de criações linguísticas, mesmo com base nas já existentes, é mais frequente.

Uma das primeiras adaptações ocorreu com a representação da oralidade na escrita, com a criação de signos para determinar pausas, entonações, volume da voz, além da utilização de espaços em branco para organização da mensagem em períodos lexicais e sintáticos. Para Marcuschi (2001), a oralidade destinou-se a ser prática social com fins comunicativos, fundamentada na realidade sonora, enquanto que a escrita é um modo de produção textual-discursiva, constituída por simbologia gráfica e/ou pictórica, na qual marcas de pontuação, letras maiúsculas e espaços são utilizados para determinar o limite de cada palavra numa oração (BRAGA, 2013).

Independentemente dos meios utilizados, a sociedade encontrou formas de se comunicar, porém, durante esse processo, foi preciso que os indivíduos conhecessem o código para compreender as mensagens. Inicialmente, apenas conhecer os signos e as construções lexicais foi 
suficiente, porém variantes contextuais passaram a influenciar a compreensão da mensagem. $O$ contexto passou a ser determinante na identificação/uso das linguagens (na comunicação), pois reúne informações que revelam características do grupo que interage, as chamadas pistas de contextualização (GUMPERZ, 2002).

$\mathrm{O}$ processo interacional pode ser descrito, portanto, pelo envolvimento de pelo menos duas pessoas, com objetivo e/ou conhecimento prévio em comum, e que dividem momentos de locução e interlocução, numa mútua construção de sentido. As representações contextuais não verbais influenciam a produção verbal, quando se constrói uma fala tomando a do outro como base (FÁVERO et al., 2010). Este processo envolve um fenômeno de figuração, que utiliza representações dos interlocutores, de acordo com a necessidade do momento (KOCH, 2006), alternando suas faces, em função do ambiente, das pessoas ao redor, das atividades a serem realizadas etc..

Nos espaços escolares, os incentivos à comunicação são frequentes, principalmente por sua heterogeneidade; e, considerando a construção de referências pessoais após a troca comunicacional em um grupo (PRADO e ALMEIDA, 2007), entende-se que um pouco de cada membro passa a fazer parte do outro, como aprendizado, ainda que imperceptivelmente. $\mathrm{O}$ resultado do processo de interação, ou seja, o aprendizado, evidencia a importância de incentivar a colaboração e o compartilhamento de conhecimentos naquele espaço escolar. De acordo com os autores, a rede de aprendizagem constitui-se complexa por considerar o contexto dos indivíduos, com sua linguagem, cultura, visão de mundo, dos outros e de si próprio. 
Tratando-se de contexto, os alunos do século XXI vivenciam práticas dialógicas amparadas por suportes informacionais geralmente distintos dos utilizados por seus professores. Esses dois grupos, em ambientes online, por exemplo, podem compartilhar suas experiências e contribuir com suas próprias formações, rumo a criação de uma comunidade. O comprometimento do membro ao grupo é alcançado quando há uma partilha de interesses em comum e quando as regras e normas pré-estabelecidas são incentivadas e respeitadas.

As comunidades escolares atuais, no entanto, possuem elementos que pouco tem despertado o interesse dos alunos, como a padronização do currículo, do livro didático e das atividades escolares. Os ambientes online podem ser personalizados para atender a estes elementos, porém segundo a relevância estabelecida pelos discentes. A educação a distância é resultado dessa democratização, pois, ao aluno, é permitido estudar e formar-se usando a tecnologia impressa, radiofônica, televisiva ou digital-online (MOORE e KEARSLEY, 2007), sem deslocar-se até a instituição formadora.

É importante ressaltar que, como apontam Palloff e Pratt (2013) e Prado e Almeida (2007), ensinar online não é um simples processo de transposição das práticas presenciais para o meio digital, uma vez que "induz a perder elementos específicos fundamentais da presencialidade" e "não incorpora as características dos recursos do ambiente virtual" (PRADO e ALMEIDA, 2007, p. 68).

Neste sentido, a cultura atual converge em sentidos diversos, num sistema multissemiótico de textos, imagens, sons, vídeos, hiperlinks, animações, emoticons, simulações 
e games, permitindo, por fim, a criação de mensagens semanticamente ricas (MOITA, 2007). Os artifícios utilizados para suprir a falta da entonação da voz, dos gestos e até do próprio silêncio compõem o que Crystal (2005, p. 89-90) chamou de netspeak, "mais compreendido como uma linguagem escrita que foi empurrada em direção à fala do que uma linguagem falada que foi escrita". Para o autor, o netspeak é mais que um conjunto de características da fala e da escrita, precisa ser visto como uma nova forma de comunicação, um novo veículo, pois suas mensagens possuem fluidez, simultaneidade e não perdem seu valor pelas cópias realizadas.

Há, no entanto, um dilema enfrentado pelos grupos que desejam utilizar-se do meio digital: precisam aprender regras que não existem, "no sentido de modos de comportamento universalmente aceitos e estabelecidos pelo uso de gerações" (CRYSTAL, 2005, p. 79). A ausência de limites sobre a criatividade em elaborar códigos linguísticos, de certa forma, força a ampliação dos conhecimentos do receptor, que busca decifrar a mensagem e extrair dela todos os possíveis sentidos.

Como contribuição à discussão, Madalena (2013) lembra mais dois pontos importantes: 1) a simbologia imagética e a contração de palavras, muitas vezes, são justificadas pela necessidade de escrita rápida, em comunicações em tempo real, contudo, quando em situações assíncronas, pode se tornar "uma falta de cortesia obrigar o leitor a um esforço desnecessário de decodificação da mensagem" (MADALENA, 2013, p. 47); mas, por outro lado, 2) os códigos podem ser considerados linguagens universais, compreendidas por grupos de línguas maternas distintas. 
Para Crystal (2005), existem três diferenças básicas entre a conversa face a face e a mediada por computador: a) a interação presencial possui retorno instantâneo, ainda que não seja em locução, os interagentes reagem instintivamente; b) é possível, em ambiente virtual, conduzir um número significativamente maior de conversas simultâneas; e c) "as limitações temporais da tecnologia: o ritmo de uma interação na Internet é muito mais lento do que o de uma situação de fala, e invalida algumas das propriedades mais evidentes de uma conversa" (CRYSTAL, 2005, p. 82). Para o autor, alguns dos fatores que influenciam tal ritmo são o computador, a personalidade e os hábitos do interlocutor em relação ao próprio acesso ao equipamento.

Quanto à tipografia da escrita em meio digital, Crystal (2005) identificou três características: a) a letra maiúscula, muitas vezes ausente por significar uma interação a mais com o teclado, não é prática comum, mas, quando ocorre, pode representar uma "forma marcada de comunicação" (op. cit., p. 93), como gritos ou ênfase ao que está sendo dito; b) a pontuação costuma ser "truncada" pela velocidade na digitação ou por escolha, provocando ambiguidades na mensagem (como em "estou com dificuldades de tirar dúvidas. a atividade IV estou com problemas. algumas respostaaaaaaa"3); e c) a grafologia da internet, que sintetiza também as combinações de símbolos, como as reticências para expressar pausa ou o excesso de sinais de pontuação indicando urgência na afirmação ou no questionamento ("Gostaria de ter acesso as notas, como faço???"4).

3 Exemplo retirado do curso de Pós-Graduação analisado

4 Exemplo retirado do Curso de Pós-Graduação analisado 
Esses registros interacionais culminam na persistência da mensagem (CRYSTAL, 2005), possível apenas em ambientes online. Os interlocutores, mesmo os ingressantes após o início da conversa, podem ter acesso ao diálogo completo, retornar ao assunto ao emitir suas impressões ou permanecer em silêncio. Este é um recurso de auxílio ao professor, por exemplo, que busca avaliar seus alunos durante o processo de aquisição de conhecimento, com base na ação interacional.

\section{A formação docente online}

O professor de ensino presencial, que, segundo Moran (2007), assume papeis previsíveis, mosaicos, papagaios e desesperançadores, precisa lidar, no ensino online, com uma interação relativa e com a ausência simultânea dos membros do grupo, levando à autonomia do aluno quanto ao momento do estudo, ao momento da avaliação e ao material consultado. Esses itens, identificados como diálogo, autonomia e estrutura, fazem parte da tríade relacional definida pela Teoria da Distância Transacional (MOORE e KEARSLEY, 2007), que determina o distanciamento emocional resultante da combinação daqueles itens, conforme apresentado a seguir.

Relação entre estrutura, diálogo e distância transacional

\begin{tabular}{|c|c|c|}
\hline Estrutura & Diálogo & Distância transacional \\
\hline Muito & Pouco & Grande \\
\hline Pouco & Muito & Pequena \\
\hline
\end{tabular}


Neste quadro, autonomia e distância apresentam-se diretamente proporcionais (quanto mais autônomo, mais independente - distante - do sistema o aluno será), em detrimento do nível de diálogo estabelecido, que aproximará os envolvidos no processo. Segundo Peters (2006), o diálogo vai além da função de aproximação ou de recurso para auxiliar os alunos:

Atualmente, a participação no diálogo ativa e intensifica a reflexão sobre problemas científicos. Trocando ideias diferentes, colocando opinião contra opinião, assumindo posições, pondo sempre de novo em dúvida conclusões e exercendo crítica, os estudantes adquirem nova relação com o conteúdo discutido, ao contrário do que ocorre quando tomam conhecimento dele apenas por leitura e reflexão e somente assimilam verdades. $\mathrm{O}$ interesse no objeto aumenta: reconhece-se um grau mais elevado de envolvimento, que pode chegar até o engajamento (PETERS, 2006, p. 78)

A prática online do professor e do aluno dependerá do nível de envolvimento/engajamento com a proposta, e com seus pares. Para tal, Palloff e Pratt (2013) definiram cinco fases do desenvolvimento do docente, identificadas no reconhecimento de sua descrição: a) o visitante não possui grande afinidade com a tecnologia, porém a experimentou e achou curiosa a integração de práticas; 
b) o principiante nunca lecionou online, mas já utilizou o espaço para disponibilizar materiais ou comunicar-se com os alunos; c) o aprendiz desenvolve maior compreensão do ambiente online, pois já passou por experiências de ensino utilizando esse ambiente; d) o iniciado é proficiente no gerenciamento de cursos, além de reunir habilidades necessárias ao ensino e ao design desses cursos; e) o mestre possui conhecimentos suficientes para utilizar recursos além dos ofertados pelo sistema, auxiliando os profissionais iniciantes.

Para que haja avanço entre essas fases é necessário treino, conhecimento e aprofundamento, ou seja, uma formação diferenciada, visando "assegurar alto grau de interatividade e participação, o que significa elaborar e conduzir atividades de aprendizagem que resultem em envolvimento com a disciplina e com os colegas" (KEARSLEY, 2011, p. 81). O profissional, portanto, precisa envolver-se com a proposta de tal forma a transmitir aos alunos segurança e confiança na aprendizagem, além de ser

organizado; altamente motivado e entusiasmado; comprometido com o ensino; apoia a aprendizagem centrada no estudante; aberto a sugestões; criativo; assume riscos; gerencia bem o tempo; atento às necessidades dos alunos; disciplinado; interessado no ensino online sem nutrir expectativas por outras recompensas. (PALLOFF e PRATT, 2013, p. 26) 
É evidente que, além da didática do profissional, existem estratégias específicas para cada ambiente de aprendizagem, que se utilizam dos seus recursos disponíveis. Um curso b-learning (aprendizagem misturada), por exemplo, pode fornecer suporte presencial às atividades virtuais ou vice e versa, usufruindo diretamente do melhor que os dois ambientes tem para oferecer, além de diminuir o impacto da aprendizagem totalmente destituída de presença física.

Esta dinâmica é prevista em Lei, pela Portaria ${ }^{\circ} 4.059$, de 10 de dezembro de $2004^{5}$, e permite a inserção de disciplinas na modalidade semipresencial em cursos de graduação, apoiadas por suportes de cunho tecnológico remoto, não ultrapassando $20 \%$ da carga horária total do curso. Essa possibilidade abre espaço para novas experiências e discussões, deixando a cargo das instituições a adoção de práticas a distância ou não.

O interesse do educador pode surgir em sua própria vivência como coprodutor virtual de saberes, ao perceber as potencialidades da união do ambiente online com o offline. De acordo com Alves (2007, p. 118), professores participantes de um curso de formação, "tendem a reproduzir o modelo vivenciado como aluno", numa intervenção de ordem reflexiva. A formação necessária para um curso b-learning pode nascer da própria experiência do professor enquanto aluno, pois perceberá as necessidades, as curiosidades e o processo de desenvolvimento cognitivo.

5 Disponível em < http://portal.mec.gov.br/sesu/arquivos/ pdf/port4059-2004.pdf > Acesso em 27 de março de 2015 
Sendo colaborativa, a aprendizagem docente, para Bolzan e Isaia (2010), configura-se no processo de apreender a partir da análise e na interpretação das suas atividades, de seus colegas e dos próprios alunos. Aqui, o principal aspecto a ser considerado é a compreensão da necessidade constante de atualizações, afinal o ambiente de trabalho deste profissional é, por função social, um espaço de aprendizagem. O educador precisa ser receptivo às novas formas de constituir o conhecimento específico e o pedagógico experimental (BOLZAN e ISAIA, 2010).

A formação continuada de professores surgiu com a necessidade de, entre outros aspectos, compensar a formação inicial, incluindo atividades discursivas de autoavaliação, de ordem pedagógica, técnica ou tecnológica. A urgência desses momentos está relacionada ao aumento da escolarização da população, à sua inserção no mercado de trabalho mundial (OLIVEIRA, 2012) e à busca por profissionais da educação mais flexíveis e versáteis, que acompanhem as exigências sociais atuais.

Segundo Filatro (2010), há uma forte tendência ligando a educação online a um processo descontextualizado, pois atende um grande número de pessoas em situações geográfica, social e culturalmente distintas. Por este mesmo motivo, no entanto, esta educação apresenta um leque de possibilidades de crescimento pessoal e profissional, inclusive atendendo àquelas exigências sociais, ao efetivar os saberes construídos num contexto em rede. A "desterritorialização do ensino vem acompanhada também por transformações no perfil daqueles que aprendem: adultos amadurecidos pelas experiências de vida e do trabalho, ou gerações mais novas moldadas em uma sociedade mediada por tecnologias" (FILATRO, 2010, p. 36). 
A aliança entre o ensino online e a formação continuada de professores tem obtido êxito, por resultar em custo-benefício positivo para instituições formadoras (públicas ou particulares), ao passo que atinge um volume massivo de profissionais, inclusive em serviço. Diante disto, podem-se identificar três potenciais efeitos: a) a apresentação de alternativas para estabelecer contato além-classe com os alunos, permitindo envolvimento afetivo, aspecto importante para o relacionamento e a construção de confiança mútua entre professor e aluno; b) a novidade que isso representa, como proposta para dinamização dos momentos presenciais; e c) a diminuição da resistência e do medo de experimentar as inovações tecnológicas.

A relevância de intensificar a convergência das mídias nos processos de formação docente (inicial ou continuada) é justamente para barrar a tendência à reprodução dos alunos quando em suas funções profissionais, tornando-os mais seguros para explorar as opções em metodologias e recursos de suporte inovadores.

\section{Percurso metodológico}

O estudo de uma cultura, sob o ponto de vista qualitativo, recebeu o nome de etnografia, e tem foco no processo da descrição do ambiente, não no resultado (ANDRE, 2008). Quando essa cultura manifesta-se também em ambientes virtuais, novos aspectos devem ser considerados, ainda que, segundo Amaral (2010), os espaços online e offline sejam indissociáveis, por compartilharem seus objetos centrais: os indivíduos. Esses novos aspectos são nomeados e descritos pela netnografia, e, para Kozinets (2014, p. 61-62), define-se como uma "pesquisa 
observacional participante baseada em trabalho de campo online", ou seja, exige que o pesquisador envolva-se com a comunidade estudada, para que seja possível descrevê-la e interpretá-la fielmente, a partir de instrumentos como entrevistas online, e-mails, postagens e sites (AMARAL, NATAL e VIANA, 2008; e ROCHA e MONTARDO, 2005).

O ambiente virtual analisado objetivou a formação continuada de profissionais da educação do Estado da Paraíba, em parceria com a Universidade Estadual da Paraíba, num curso de Pós-Graduação Lato Sensu em Fundamentos da Educação: Práticas Pedagógicas Interdisciplinares. A proposta seguiu em eixos temáticos (Educação e Identidade; Educação e Tecnologia; Educação e Campo; Educação e Cidadania; Educação e Cultura; Educação e Cidade; Educação e Comunicação; Educação e Trabalho; e Educação e Pesquisa) de forma modularizada, atendendo a cada segmento.

As aulas presenciais (200 horas) ocorreram aos sábados, em polos localizados em cidades paraibanas, e os encontros a distância, no ambiente virtual de aprendizagem (Moodle), com 160 horas, levando os 3.159 professores $^{6}$ a vivenciar uma experiência totalmente nova para muitos. Houve também distribuição de material didático e realização de um momento presencial de ambientação para a utilização do Moodle.

Dentre os módulos do curso, foi escolhido o de Comunicação e Linguagem e a Turma 5 (Paulo Freire). Este módulo durou cinco semanas temáticas (de 1으 de agosto a 5 de setembro de 2013), e a terceira ("A escola,

6 Disponível em < http://ead.uepb.edu.br/noticias,487 > Acesso em 21 de abril de 2015. 
nativos digitais e suportes digitais") forneceu os diálogos aqui analisados e categorizados.

Esse processo ocorreu sem referência prévia, pois são dados extraídos de documentos virtuais, que induzem à elaboração de códigos ou categorias a partir de uma leitura mais atenta, servindo como rótulos ou exemplos do fenômeno descrito (KOZINETS, 2014). As categorias identificadas foram "Saudação Inicial", "Interação" e "Encerramento da Mensagem", com subcategorias, dependendo da discussão. Foram também observados quantidade de postagens do professor mediador e dos alunos, o uso da linguagem formal e da netspeak ${ }^{7}$, o conteúdo dos comentários (nível da reflexão e elementos da mensagem) e a disposição dos alunos em interagir. Não houve exposição de nomes ou de informações que pudessem constranger ou intimidar os participantes.

\section{A voz do Docente enquanto Discente}

Como mecanismo de defesa, o ser humano, ao se deparar com uma situação nova, tende a resistir ao enfrentamento, preservando-se diante do desconhecido. No entanto, esse desconhecido reúne oportunidades de aprendizagem, que levam o indivíduo para além de sua zona de conforto, desafiando a construção de novos conceitos ou o reestabelecimento dos existentes.

7 Segundo Crystal (2005), uma nova forma de comunicação em ambientes virtuais, que agrega fluidez, simultaneidade em diferentes combinações de códigos. 
O grupo estudado nesta pesquisa, por exemplo, é proveniente de um curso de formação continuada b-learning para educadores, sendo que, para muitos deles, a comunidade virtual é um ambiente desconhecido. Diante disto, os estímulos e o suporte para promover o engajamento ao grupo precisaram ser intensos, na utilização de recursos digitais de fácil manuseio e diálogos amigáveis.

Durante a semana analisada, foram disponibilizados alguns arquivos: (a) uma apresentação da disciplina em formato de áudio; (b) dois materiais de leitura ("Nativos digitais x Aprendizagem: um desafio para a escola" e "Nativos digitais versus imigrantes digitais: a controvérsia"); (c) uma apresentação de slides abordando o tema; e (d) um vídeo intitulado "Conheça o aluno multimídia".

O fórum foi classificado como Atividade, com o seguinte enunciado: "Faça uma leitura crítica das diferentes linguagens apresentadas nesta semana e escreva no fórum uma frase reflexiva com 2 linhas. [link para o fórum: Fórum]". O acesso a esse item não possui indicação direta nos materiais de leitura ou na apresentação de slides, o que facilitaria o fluxo das ações, sendo necessário voltar à página inicial para acessá-lo.

Com esses dados, percebe-se a intenção de promover o reconhecimento da identidade e do formato do curso a ser iniciado. Os alunos precisam perceber e ter acesso ao planejamento do curso, com os objetivos pretendidos e as habilidades e competências esperadas, ao final do percurso (MOORE e KEARSLEY, 2007; PETERS, 2006). É importante, também, que essa apresentação seja amigável, objetiva e dinâmica, para despertar e manter a atenção e a curiosidade do participante. 
A primeira postagem do mediador da turma Paulo Freire foi composta pelo texto oficial da Atividade, com o objetivo da discussão e a quantidade máxima de linhas para a resposta, porém sem elementos de saudação inicial ou final e assinatura.

Primeira postagem do mediador da Turma 5

Além desta, o professor mediador participou mais duas vezes. Na primeira delas, parabenizou os alunos, motivando-os com uma linguagem coloquial - buscando a construção de vínculos afetivos (KERCKHOFF, 2014, p. 31) -, e sem erros gramaticais ou de digitação: “Muito bem, pessoal. Muito bem mesmo! Estou gostando do nível dos comentários.". Além disto, comentou sobre o que foi discutido até então ("Tenho uma pequena observação sobre alguns pontos de vistas"), mas sem identificar os alunos a quem se referia. Percebe-se o teor reflexivo da postagem em questionamentos, como "Por que eu digo isso?" e "Não concordam?", e a busca por incluir-se ao grupo, por meio da conjugação dos verbos na terceira pessoa do plural ("nós devemos direcionar o aprendizado", "Então, somando todo o nosso conhecimento").

A última postagem manteve o padrão da linguagem coloquial e o respeito às normas gramaticais, mas explorou um pouco mais os recursos linguísticos, como as reticências, indicando surpresa e admiração em 
"Pessoal... sem palavras." e as letras maiúsculas na palavra "todos" ("Estou muito satisfeito com o desempenho de TODOS vocês"), amplificando/destacando seu sentido (MADALENA, 2013). O conteúdo desta mensagem foi de cunho motivacional e de reconhecimento pela participação dos alunos, quando explicitou seu orgulho pelo nível de interação da turma. A postagem finaliza com uma solicitação da opinião dos alunos sobre o novo formato do fórum.

As respostas aos comentários do mediador envolveram concordância com sua opinião, relatos de experiências sobre o tema, agradecimentos exaltados por excesso de exclamações e confirmação da importância da participação naquela discussão ("Muito legal o fórum, parabéns por fazer parte do mesmo junto conosco." e "Estou muito feliz com o seu comentário, estou realmente muito satisfeita por fazer parte deste grupo."), autoavaliação ("escrevi pouco, mas consegui ler quase todas as interações"), cumprimentos pela organização e pelo curso, e alunos cobrando a participação dos colegas, utilizando aspas e negrito para chamar a atenção ("vamos 'lembrar' aos nossos colegas de participarem desse fórum e contribuírem com as trocas cognitivas para que possamos enriquecer cada vez mais nossas práticas pedagógicas!").

Foram realizadas 204 postagens no fórum, contabilizando 306 respostas, das quais 51 eram repetições, que podem estar relacionadas a questões técnicas, como lentidão da conexão, que dá a impressão de não envio da resposta (demora um pouco para aparecer na tela), levando o aluno a clicar diversas vezes para enviar. Algumas respostas (98) ultrapassaram a orientação sobre a quantidade máxima de linhas, o que leva a um ponto de reflexão: se 
há uma orientação sobre como responder uma atividade, os alunos deverão segui-la à risca, exercitando habilidades específicas, como a de organização direta e objetiva das ideias; porém o nível de interação dos participantes pode ser maior quando há exposição de suas opiniões com clareza e riqueza de detalhes.

Alguns participantes se destacaram assumindo um papel provocador num processo de aprendizagem docente colaborativa (BOLZAN e ISAIA, 2010):

Situações de interação no fórum

\begin{tabular}{|c|c|}
\hline \multicolumn{2}{|r|}{ Situação 1 - Burocracia auxilia ou atrapalha? } \\
\hline$[\mathrm{A}]$ & $\begin{array}{l}\text { "Colegas, o grande problema é que a escola está as margens } \\
\text { das múltiplas oportunidades tecnológicas extra território } \\
\text { escolar.Não será a burocracia a grande vilã? Os tablets?" }\end{array}$ \\
\hline [B] para $[\mathrm{A}]$ & $\begin{array}{l}\text { "De forma alguma professora [A], estas "burocracias" } \\
\text { são apenas ferramentas para facilitar e acelerar nossa } \\
\text { aprendizagem e consequentemente à do nosso aluno. } \\
\text { Antes, os alunos tinham que ir fazer pesquisas nas } \\
\text { bibliotecas,desarrumavam uma pilha de livros e hoje nada } \\
\text { disso mais é preciso, sem contar que na webquest ele } \\
\text { encontra excelentes leituras, pode ir à inúmeras bibliotecas } \\
\text { virtuais sem sair de casa." }\end{array}$ \\
\hline \multicolumn{2}{|r|}{ Situação 2 - Familiaridade com a tecnologia } \\
\hline$[\mathrm{A}]$ & $\begin{array}{l}\text { "Atualmente os jovens são os primeiros a se inserir nas } \\
\text { tecnologias digitais de comunicação, permitindo está } \\
\text { interligado com a sociedade contemporânea." }\end{array}$ \\
\hline$[\mathrm{B}]$ para $[\mathrm{A}]$ & $\begin{array}{l}\text { "E porque iniciam tão cedo ou já aprendem as peimeiras } \\
\text { letras no teclado,ao contrário de nós que aprendíamos } \\
\text { na boa e velha tabuada e do alfabeto plástico, são então } \\
\text { chamados de "Nativos Digitais"” }\end{array}$ \\
\hline$[\mathrm{C}]$ para $[\mathrm{B}]$ & $\begin{array}{l}\text { "É verdade professora [B],eles não vem limites,já nós...e } \\
\text { o que achas que deve ser feito para acompanharmos os } \\
\text { nativos digitais [B] ?" }\end{array}$ \\
\hline
\end{tabular}


Apesar de tímidas e pouco exploradas, as interações podem indicar um desejo por discutir o assunto naquele espaço, mesmo sem uma solicitação inicial ou um incentivo frequente a esta prática. A utilização de saudação, assinatura ou referência ao comentário de outros participantes também foi pequena. A seguir são descritas as formas iniciais de interação entre os participantes, com os rótulos criados a partir da leitura dos dados, sem uma codificação prévia (KOZINETS, 2014). A categoria "Saudação Inicial" reúne alguns textos encontrados no início das mensagens:

Categoria "Saudação Inicial"

\begin{tabular}{|c|c|c|}
\hline Subcategoria & Descrição/Função & Ocorrências \\
\hline $\begin{array}{l}\text { Chamamento } \\
\text { formal }\end{array}$ & $\begin{array}{l}\text { O uso dos vocativos "caro" e "prezada" } \\
\text { demonstram formalidade e cordialidade, } \\
\text { apesar de, em alguns casos, precederem } \\
\text { um substantivo informal. Nomear a quem } \\
\text { está se referindo pode indicar um canal } \\
\text { comunicativo direto, dentre as outras } \\
\text { interações. }\end{array}$ & $\begin{array}{l}\text { "Caros (a) } \\
\text { colegas"; } \\
\text { "Caros colegas!"; } \\
\text { "Prezada colega,"; } \\
\text { "Caro [nome do } \\
\text { mediador]," }\end{array}$ \\
\hline $\begin{array}{c}\text { Chamamento } \\
\text { informal }\end{array}$ & $\begin{array}{l}\text { Ainda que varie em número e em } \\
\text { direcionamento a uma pessoa ou ao } \\
\text { grupo, esses exemplos buscam um } \\
\text { maior nível de proximidade afetiva, } \\
\text { pois refletem expressões utilizadas em } \\
\text { diálogos presenciais. }\end{array}$ & $\begin{array}{l}\text { “Olá [nome]”; } \\
\text { “Olá colegas"; } \\
\text { “Oi pessoal!"; } \\
\text { "Colegas, [...]" }\end{array}$ \\
\hline $\begin{array}{c}\text { Misto de } \\
\text { chamamentos }\end{array}$ & $\begin{array}{l}\text { A junção das duas subcategorias } \\
\text { anteriores apresenta uma saudação } \\
\text { formal, mas que foi suavizada pela } \\
\text { palavra "amigos" e a exclamação. }\end{array}$ & $\begin{array}{l}\text { "Saudações } \\
\text { amigos!"; }\end{array}$ \\
\hline
\end{tabular}




\begin{tabular}{|c|l|l|}
\hline Subcategoria & \multicolumn{1}{|c|}{ Descrição/Função } & \multicolumn{1}{c|}{ Ocorrências } \\
\hline $\begin{array}{c}\text { Incentivo e } \\
\text { congratulações }\end{array}$ & $\begin{array}{l}\text { O cursista incentivador demonstra } \\
\text { familiaridade com o ambiente, pois o } \\
\text { faz sem que haja solicitação de terceiros } \\
\text { e tomam a iniciativa de parabenizar os } \\
\text { colegas, nomeando-os, ou não. }\end{array}$ & $\begin{array}{l}\text { "Parabéns } \\
\text { colega!"; } \\
\text { "Cara [nome], } \\
\text { parabéns por suas } \\
\text { colocações !"; }\end{array}$ \\
\hline Por turno & $\begin{array}{l}\text { A identificação do turno em que a } \\
\text { mensagem está sendo postada implica } \\
\text { cordialidade, mas, também, o momento } \\
\text { em que o aluno acessa o sistema. A este } \\
\text { fator é atribuído um sentido único da } \\
\text { mensagem, e ao recebê-la em outro turno, } \\
\text { o leitor poderá encontrar-se em conflito } \\
\text { com sua realidade. }\end{array}$ & $\begin{array}{l}\text { "Boa noite } \\
\text { pessoal."; } \\
\text { "Bom dia[nome } \\
\text { do mediador]!"; } \\
\text { "Caro [nome]. } \\
\text { Bom dia." }\end{array}$ \\
\hline
\end{tabular}

A seguir, as subcategorias de "Interação", considerando os conteúdos das mensagens e as menções aos membros do grupo, direta ou indiretamente.

Categoria "Interação"

\begin{tabular}{|c|c|c|}
\hline Subcategoria & Descrição/Função & Ocorrências \\
\hline $\begin{array}{c}\text { Questionamento } \\
\text { retórico }\end{array}$ & $\begin{array}{l}\text { Ainda que possa parecer um } \\
\text { questionamento retórico, a aluna abriu } \\
\text { espaço para discussão, solicitando a } \\
\text { opinião de um colega acerca de sua } \\
\text { própria condição, frente às tecnologias } \\
\text { digitais. }\end{array}$ & $\begin{array}{l}\text { "Companheiro, }[\ldots] \\
\text { será que um dia serei } \\
\text { uma nativa digital?" }\end{array}$ \\
\hline $\begin{array}{c}\text { Questionamento } \\
\text { direto }\end{array}$ & $\begin{array}{l}\text { Para incentivar a discussão do tema, } \\
\text { o autor dessa mensagem utilizou } \\
\text { de um simples e eficaz artifício: o } \\
\text { questionamento. }\end{array}$ & $\begin{array}{l}\text { "E como seria essa } \\
\text { transformação } \\
\text { professora }[\text { nome }] ? "\end{array}$ \\
\hline
\end{tabular}




\begin{tabular}{|c|c|c|}
\hline Subcategoria & Descrição/Função & Ocorrências \\
\hline $\begin{array}{c}\text { Concordância } \\
\text { ou discordância } \\
\text { direta (nominal) }\end{array}$ & $\begin{array}{l}\text { Esses exemplos demonstram a } \\
\text { participação dos membros do grupo } \\
\text { (concordando ou discordando), } \\
\text { contribuindo com a fala do outro e } \\
\text { construindo saberes coletivamente. } \\
\text { Nomear um colega, apesar de parecer } \\
\text { desnecessário, é importante para } \\
\text { intensificar o vínculo afetivo. Vale } \\
\text { lembrar que a utilização das palavras } \\
\text { "amiga" e "professor" indicam níveis } \\
\text { de empatia que podem ser decorrentes } \\
\text { do presencial. }\end{array}$ & $\begin{array}{l}\text { "De forma alguma } \\
\text { professora [nome],"; } \\
\text { "E eu, acredito } \\
\text { professora [nome] } \\
\text { que"; } \\
\text { "Concordo com } \\
\text { a amiga [nome] } \\
\text { quando"; }\end{array}$ \\
\hline $\begin{array}{l}\text { Agradecimento } \\
\text { direto (não } \\
\text { nomeado) }\end{array}$ & $\begin{array}{l}\text { Este intenso comentário, apesar de } \\
\text { não possuir um endereçamento, foi } \\
\text { realizado como resposta a algum } \\
\text { elogio. É possível concluir isto pela } \\
\text { organização mensagens, na qual uma } \\
\text { resposta é alocada logo abaixo da } \\
\text { postagem a que faz referência, com um } \\
\text { recuo à direita. }\end{array}$ & $\begin{array}{l}\text { “Fico feliz!!!! muito } \\
\text { obrigada!!!!” }\end{array}$ \\
\hline $\begin{array}{c}\text { Resposta direta ao } \\
\text { mediador }\end{array}$ & $\begin{array}{l}\text { Esses dois exemplos foram respostas } \\
\text { nomeadas ao mediador, que solicitou } \\
\text { a opinião dos alunos acerca do } \\
\text { novo formato do fórum. O uso dos } \\
\text { identificadores "professor" ou "prof" } \\
\text { demonstra respeito à posição do } \\
\text { mediador, mesmo todos sendo, por } \\
\text { profissão, também professores. }\end{array}$ & $\begin{array}{l}\text { "Prof. [nome do } \\
\text { mediador], gostei } \\
\text { desse novo modelo } \\
\text { de fórum,"; } \\
\text { "esse novo modelo } \\
\text { está excelente } \\
\text { professor." }\end{array}$ \\
\hline Incentivo à equipe & $\begin{array}{l}\text { A atitude de parabenizar a equipe } \\
\text { tem um teor motivacional importante } \\
\text { para o andamento do curso, uma vez } \\
\text { que este grupo necessita perceber } \\
\text { um retorno dos alunos quanto ao seu } \\
\text { trabalho, para continuar realizando-o. }\end{array}$ & $\begin{array}{l}\text { "Aplausos para } \\
\text { esta equipe } \\
\text { organizativa!" }\end{array}$ \\
\hline
\end{tabular}

\section{Por fim, a categoria "Encerramento da Mensagem" e suas subcategorias, elaboradas com a análise dos textos localizados ao final das mensagens.}


Categoria "Encerramento da Mensagem"

\begin{tabular}{|c|c|c|}
\hline Subcategoria & Descrição/Função & Ocorrências \\
\hline Nome da pessoa & $\begin{array}{l}\text { Variando em apenas o primeiro } \\
\text { nome e o nome completo ou } \\
\text { acrescentando "Prof", a incidência } \\
\text { desta subcategoria é baixa, levando } \\
\text { a crer que os alunos compreendem } \\
\text { a autoidentificação que o próprio } \\
\text { sistema fornece no ato da postagem } \\
\text { da mensagem. }\end{array}$ & [nome do aluno] \\
\hline $\begin{array}{l}\text { Despedida formal } \\
\text { ao grupo }\end{array}$ & $\begin{array}{l}\text { A abreviação da expressão } \\
\text { "Atenciosamente" (Att) denota } \\
\text { uma formalidade comum em troca } \\
\text { de e-mail, apesar de o formato } \\
\text { geralmente utilizar outro sinal de } \\
\text { pontuação ("Atenciosamente,", } \\
\text { "Att," ou "Att"). }\end{array}$ & "Att: [nome do aluno]" \\
\hline $\begin{array}{l}\text { Despedida } \\
\text { informal }\end{array}$ & $\begin{array}{l}\text { Seja no singular seja no plural, } \\
\text { individualmente ou para todo } \\
\text { o grupo, encerrar a mensagem } \\
\text { mandando abraços ou beijos } \\
\text { representa um nível de } \\
\text { envolvimento afetivo semelhante } \\
\text { ao que se encontra em encontros } \\
\text { presenciais, quando são realizados } \\
\text { ou apenas ditos na despedida. Os } \\
\text { exemplos podem ser interpretados } \\
\text { como uma finalização automática } \\
\text { e amigável da mensagem, para } \\
\text { que o seu conteúdo não se limite à } \\
\text { solicitação do fórum. }\end{array}$ & $\begin{array}{l}\text { "Abraço"; } \\
\text { "Abraços"; } \\
\text { "Um forte abraço."; } \\
\text { “Tenham todos uma } \\
\text { boa noite."; } \\
\text { "Abraços [nome do } \\
\text { aluno]. Fica com } \\
\text { Deus." }\end{array}$ \\
\hline
\end{tabular}




\begin{tabular}{|c|c|c|}
\hline Subcategoria & Descrição/Função & Ocorrências \\
\hline $\begin{array}{c}\text { Despedida } \\
\text { composta }\end{array}$ & $\begin{array}{l}\text { A união do desejo de sucesso } \\
\text { com uma referência de saudação } \\
\text { formal adaptada demonstra um } \\
\text { nível de elaboração acentuado, } \\
\text { descaracterizando uma } \\
\text { finalização automática. O aluno } \\
\text { fez também referência a sua } \\
\text { condição profissional, afirmando } \\
\text { envolvimento afetivo com a } \\
\text { atividade, ao incluir a expressão } \\
\text { "Saudações didáticas" na } \\
\text { despedida. }\end{array}$ & $\begin{array}{l}\text { "Muito sucesso na } \\
\text { caminhada! } \\
\text { Saudações didáticas," }\end{array}$ \\
\hline Despedida virtual & $\begin{array}{l}\text { Essa subcategoria é a única que, } \\
\text { em interações no mundo real, não } \\
\text { se adequaria, pois faz referência } \\
\text { direta ao ambiente online. Percebe- } \\
\text { se os autores preocuparam-se } \\
\text { com a elaboração da expressão, } \\
\text { principalmente em "Saudações } \\
\text { Neanderthal e boa viagem", que } \\
\text { reuniu uma saudação formal, uma } \\
\text { referência à espécie humana e uma } \\
\text { alusão à viagem que a experiência } \\
\text { online pode proporcionar. }\end{array}$ & $\begin{array}{l}\text { “Saudações virtuais"; } \\
\text { “Abraço virtual!”; } \\
\text { “Abraços virtuais."; } \\
\text { “Saudações } \\
\text { Neanderthal e boa } \\
\text { viagem!” }\end{array}$ \\
\hline
\end{tabular}

A partir dessas categorias e subcategorias, percebe-se o rico campo semântico em que os participantes do curso estão inseridos e que apontam em suas mensagens, ainda que possam desconhecer esse potencial. A maneira com que inicia ou finaliza uma postagem demonstra o nível de interesse e envolvimento do aluno naquele curso, bem como sua disposição em voltar à discussão para interagir além do que foi solicitado. A formalidade mista, presente em boa parte dos momentos de saudação e despedida, pode representar uma tendência à informalidade, porém ainda presa a práticas tradicionais. 
Os questionamentos também fazem parte da interação, principalmente quando não se limitam à função retórica, pois buscam no grupo a construção colaborativa de algum conceito ou definição. Rabello (2011) vê, na concepção sociointeracionista de Vygotsky, aplicação às possibilidades ofertadas pela internet, apontando para um aprendiz integrante, de fato, de um grupo social, pois possui "iniciativa para questionar, descobrir e compreender o mundo a partir de interações" (op. cit., p. 27). Esses questionamentos podem ser diretos ("E como seria essa transformação professora [nome da professora]?") ou sutis (Companheiro, [...] será que um dia serei uma nativa digital?"), mas, independente da abordagem, representam uma tentativa de estabelecer um diálogo mais aprofundado acerca do assunto tratado.

Quanto aos recursos linguísticos, observou-se pouca utilização para atribuir sentido extra às postagens, porém ainda foi possível encontrar textos em cores diversas, imagens, hiperlinks, aspas em palavras-chaves (nativos e imigrantes digitais, principalmente), arquivos de texto anexados, todas as palavras da mensagem em letras maiúsculas, excesso de parágrafos e de pontuação, palavras sublinhadas e em itálico e demonstração de risada pela repetição de letras ("kkk"). 


\title{
Exemplo de mensagem com hiperlink, excesso de pontuação e aspas
}

Re: Atividade da Terceira Semana

por

\author{
- domingo, 18 agosto $2013,18: 10$
}

Os nativos digitais apreendem como comprar algo, baixar músicas, filmes, etc, de uma forma muito rápida, como também a faze uma série de coisas, mas deixa muito a desejar na hora de usar em prol da educação formal. No dia a dia em sala de aula, nós professores, "lutamos" para que as TICs tenha seu lugar, não é toda hora e nem em toda aula, pois nossos alunos precisam saber escrever segundo o padrão, não dả pra ficar só na net, acredito eu, que a net é muito importante para a aquisição de saberes nesta pós-modernidade, mas outros saberes se faz necessário para a formação humanistica do Homem. Pois se não for assim, nossos jovens em um futuro bem próximo terão uma enorme dificuldade de grafar as palavras, de se relacionarem de forma real, pois as coisas tendem a ser tudo virtual: amizades, namoros, encontros, etc. Imagine se nós não impormos os limites do uso da net na salc

de aula????... O que será do código escrito, dos valores, da moral, etc. ......... O porvir é muito tenebroso neste sentido.

\section{Exemplo de mensagem com formatações textuais, aspas e palavras em maiúsculo}

\section{Re: MARIA}

por

- segunda, 26 agosto 2013, 17:10

"A educação está passando pelo um grande desafio,diante desse novo método pedagógico que é a chegada dos Tablets nas escolas. E temos que aderir a essa inovação tecnológica ou ficamos para traz."

Prezada colega,

Os meios tecnológicos digitais assumem uma substituição das máquinas de escrever, dos mimeógrafos, dos projetores ou retroprojetores entre outros meios copiados para a EDUCAÇÃO, mas que foram criados para uso militar.

Nesse sentido, tais equipamentos vieram substituir esses multimeios citados. Na verdade, os MÉTODOS PEDAGÓGICOS perpassam ou vão além de meios tecnológicos - pontuam o ensino aprendizagem a partir dos Direitos de Aprendizagem dos alunos - pois a leitura/escrita, a escrita/leitura, análises, palestras, debates, conferências, estudo de campo, entre outros, delimitados no currículo não representa necessariamente a imposição do uso desses equipamentos.

$\mathrm{Na}$ escola onde leciono, o laboratório de informática existe, mas o sinal da web é insuficiente para as máquinas funcionarem na teia. Assim como, os tablets, também, não entram em cena, pois a INTERNET oferece péssima qualidade no sinal - uma derrocada da tecnologia.

Não somos obrigadas/os a preparar um plano de aula com tais ferramentas, apenas para satisfazer 0 interesse de terceiros.

Acalme-se e continue exercendo o seu labor de ensino aprendizagem da forma mais natural, real e acima de tudo didática com sabor e saber.

Muito sucesso na caminhada!

Saudações didáticas,

[nome da aluna]

E.

\section{Neste último exemplo, pode ser encontrada uma refe- rência à Netiqueta, quando na regra para fóruns e grupos de discussões "Colocar o texto acima da resposta". Neste}


caso, segundo Madalena (2013), torna-se mais fácil apresentar-se num diálogo organizado em ordem cronológica, além de reforçar a identificação sobre a mensagem referenciada.

Um último ponto interessante a ser relatado é a emissão de opiniões acerca do tema abordado neste trabalho. Estas colocações representam um rico celeiro de assuntos a serem abordados e discutidos entre os alunos e mediados pelo professor responsável. São opiniões que transitam entre os grupos, fora do ambiente virtual, e que podem, aqui, fazerem-se representadas, aumentando a rede de saberes de todos os envolvidos.

Comentários sobre Interação e Linguagem no fórum da Turma 5

\begin{tabular}{|c|l|}
\hline \multicolumn{2}{|c|}{ Comentários sobre Interação e Linguagem } \\
\hline A & $\begin{array}{l}\text { "A linguagem é o alicerce da cultura humana, sendo instrumento } \\
\text { de sua manifestação e desenvolvimento." }\end{array}$ \\
\hline B & $\begin{array}{l}\text { "A linguagem é uma forma ou processo de interação, é um } \\
\text { instrumento para própria cultura." }\end{array}$ \\
\hline C & $\begin{array}{l}\text { "A linguagem é uma forma de nos comunicar, assumindo um } \\
\text { papel importante de conhecer nossos valores e costume de nossa } \\
\text { cultura como também de nossa sociedade." }\end{array}$ \\
\hline D & $\begin{array}{l}\text { "Devemos nos adaptarmos as novas linguagens tecnológicas } \\
\text { para facilitar a aprendizagem dos nossos alunos a fim de } \\
\text { despertar a necessidade de compartilhar conhecimentos } \\
\text { significativos através de pesquisas, jogos educativos, projetos } \\
\text { garantindo a necessidade de juntos trocarmos experiências e nos } \\
\text { colocarmos na condição de aprendizes pois temos o domínio } \\
\text { dos conteúdos. Mas que linguagem iremos utilizar para que essa } \\
\text { comunicação se efetive de forma clara e objetiva?" }\end{array}$ \\
\hline E & $\begin{array}{l}\text { "Os nativos digitais digitais não querem ser apenas meros } \\
\text { espectadores, eles sentem a necessidade de serem atores. } \\
\text { Esperam, querem e precisam de comunicação interativa." }\end{array}$ \\
\hline
\end{tabular}


Visões interessantes e, de certa forma, criativas, foram encontradas, como no seguinte comentário: "Para o grupo dos nativos digitais (Geração Y e Z) e imigrantes digitais (Geração X), poderia ser formado um novo 'Plano cartesiano', em que a 'reta' x (Geração X) e 'reta' y (Geração Y e Z) poderiam se 'unir', formando uma reta dupla, imaginária e crescente, e todos pudessem superar os desafios e atingissem o sucesso.". O que o aluno descreveu (ilustrado abaixo) corrobora com Prensky (2001) $)^{8}$, quando defende imigrantes e nativos digitais dotados de formas diferentes de processar uma informação, mas que, com objetivo compartilhado e união de habilidades individuais, torna-se natural o processo integrador entre os sujeitos e seus saberes adquiridos.

\section{Novo plano cartesiano (proposto por aluno)}

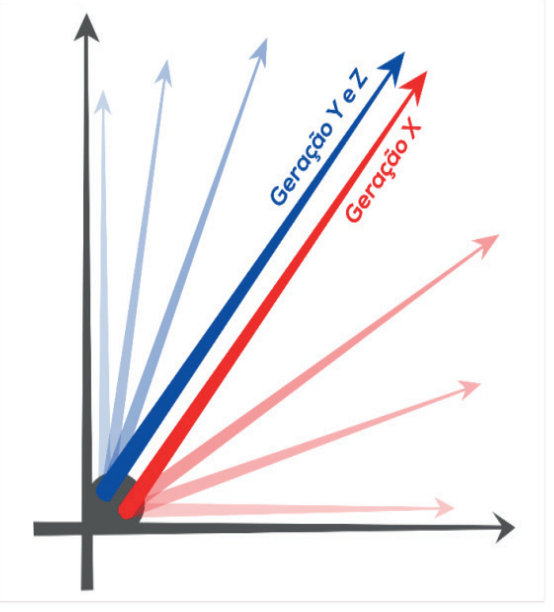

8 http://www.emeraldinsight.com/doi/pdfplus/10.1108/1074 8120110424816 
Em geral, o fórum apresentou um nível de interação pessoal considerável, apesar de, segundo Kearsley (2011), não ser uma necessidade primária para estudantes de pós-graduação. Quanto à linguagem utilizada, os participantes exploraram um pouco os recursos ofertados pelo Moodle, além do próprio texto e suas variações, o que é compreensível, por ser este um público aprendiz das tecnologias digitais. Vale salientar que, apesar disto, houve discussão e exposição das opiniões a favor da congruência de saberes entre nativos e imigrantes digitais, configurando, portanto, uma aprovação dos recursos digitais utilizados nos processos educacionais institucionalizados.

\section{Chegando ao destino}

O potencial existente no processo de interação em rede virtual, muito além da real, está nas possibilidades de representação da informação em formatos e suportes distintos, que, combinados, permitem ricas interpretações semânticas e aprendizagens significativas. Para isso, os interagentes precisam partilhar objetivos, linguagem e conhecimentos prévios, a fim de tornar a comunicação satisfatória para os envolvidos.

Os fóruns analisados reuniram professores em formação continuada (naquele momento, alunos) com o objetivo de interagir, respondendo a atividade avaliativa solicitada. $\mathrm{O}$ espaço utilizado abrigava recursos digitais e de formatação, que permitiriam um acréscimo semântico substancial ao conteúdo textual. A tímida exploração desses recursos, no entanto, pode ser justificada pelo desconhecimento da ferramenta e de suas possibilidades de uso. 
No que tange ao conteúdo das postagens, percebeu-se que a temática da semana (nativos versus imigrantes digitais) foi compreendida pelos participantes, tendo, porém, pouca variação de teor conceitual nas contribuições. É possível que a solicitação de uma frase reflexiva, com limite de duas linhas, tenha conduzido as respostas a uma mesma linha de pensamento, com base nas referências disponibilizadas anteriormente. Apesar disto, houve, também, relatos de professores que se identificaram como nativos ou imigrantes digitais, e perceberam, diante de sua práxis, a importância de discutir e de praticar as possibilidades ofertadas pelos recursos digitais.

A partir das mensagens trocadas, foram identificadas e categorizadas situações de análise do diálogo (a seguir), indicando um nível relativamente baixo de engajamento ao grupo, pois a ocorrência de mensagens apenas com a frase solicitada foi considerada superior à disposição de elementos interacionais.

- Categoria "Saudação Inicial": chamamento formal, informal, misto, informal e por turno, afetivo, informal nominal, temático, incentivo e congratulações e por turno;

- Categoria "Interação": questionamento retórico, direto, concordância ou discordância direta (nominal), agradecimento direto (não nomeado), resposta direta ao mediador, incentivo nominal e à equipe;

- Categoria "Encerramento da Mensagem": nome da pessoa, simbologia, despedida formal ao grupo, informal, intensa, composta, virtual e assinatura informativa. 
A característica mista (b-learning) do curso de PósGraduação analisado deveria proporcionar aos participantes uma representação maior da afeição construída, já que houve oportunidade de encontros presenciais, além da possibilidade de vínculos pré-existentes. No entanto, as poucas interações entre os participantes revelaram uma presença social pouco marcante, sendo esta uma questão importante a ser aprofundada em pesquisas futuras.

O professor mediador, num cenário carente de envolvimento afetivo e de contribuições inovadoras, tem a função de encorajar, reconhecer e contribuir com as postagens dos alunos, em função do que lhe é possível ter de informação (perfil e participações). Apesar da distância física - o que, neste caso, pode não ter sido total, já que houve a possibilidade de que os alunos conhecessem pessoalmente também seus professores mediadores -, estes profissionais precisam construir um ambiente envolvente e rico em feedbacks, para que o grupo e os indivíduos sintam que suas colocações estão sendo percebidas e reconhecidas.

Estas observações apontam para questões discutidas, antes de tudo, no ensino presencial, quando o diálogo é controlado por alguns poucos indivíduos. A interação em ambientes virtuais de aprendizagem, assim como a exposição dos conteúdos e o planejamento do curso e das aulas, por exemplo, tendem a repetir as dinâmicas escolares em ambientes físicos, porém inexistem elementos equivalentes o suficiente para firmar qualitativamente as transferências conceituais. É necessário adequar, nos dois ambientes, os recursos disponíveis à proposta, considerando, principalmente, os mesmos três itens, que devem ser partilhados em uma interação: o objetivo, a linguagem 
e os conhecimentos prévios do grupo. A partir disto, será possível ampliar o potencial nato do ser humano de compartilhar saberes e construir significados integrados às múltiplas formas de representação da informação.

\section{Referências}

ALVES, Aglaé Cecília Toledo Porto. EaD e a formação de professores. In: VALENTE, José Armando; ALMEIDA, Maria Elizabeth Bianconcini de (orgs.). Formação de educadores a distância e integração de mídias. São Paulo: Avercamp, 2007.

AMARAL, Adriana. Etnografia e pesquisa em cibercultura: limites e insuficiências metodológicas. In: REVISTA USP, São Paulo, n.86, p. 122-135, junho/agosto 2010. Disponível em <http://www.revistas.usp.br/revusp/ article/view/13818> Acesso em 29 de junho de 2014.

AMARAL, Adriana; NATAL, Geórgia; VIANA, Lucina. Netnografia como aporte metodológico da pesquisa em comunicação digital. In: Sessões do Imaginário, vol.13(20), 34-40, 2008. Disponível em < http://revistaseletronicas.pucrs.br/ojs/index.php/famecos/article/ download/4829/3687 > Acesso em 05 de julho de 2014.

ANDRE, Marli Eliza Dalmazo Afonso de. Etnografia da prática escolar. 14 ed. Campinas-SP: Papirus, 2008.

BOLZAN, Doris Pires Vargas; ISAIA, Silvia Maria de Aguiar. Pedagogia universitária e aprendizagem docente: relações e novos sentidos da professoralidade. In: Revista 
Diálogo Educacional, Curitiba, v. 10, n. 29, p. 13-26, 2010. Disponível em http://www2.pucpr.br/reol/index.php/ DIALOGO?dd1=3422\&dd99=pdf. Acessado em 14 de outubro de 2012.

BRAGA, Denise Bértoli. Ambientes virtuais: reflexões teóricas e práticas. São Paulo: Cortez, 2013.

CRYSTAL, David. A revolução da linguagem. Rio de Janeiro: Jorge Zahar Ed., 2005

FÁVERO, Leonor Lopes et al. Interação em diferentes contextos. In: BENTES, Anna Christina; LEITE, Marli Quadros. Linguística de texto e análise da conversação: panorama das pesquisas no Brasil. São Paulo: Cortez, 2010.

FILATRO, Andrea. Design instrucional contextualizado: educação e tecnologia. 3 ed. São Paulo: Editora Senac São Paulo, 2010.

GUMPERZ, John Joseph. Convenções de contextualização. In: RIBEIRO, Branca Telles; GARCEZ, Pedro M. (orgs.). Sociolinguística interacional. São Paulo: Editoras Loyola, 2002.

KEARSLEY, Greg. Educação on-line: aprendendo e ensinando. São Paulo: Cengage Learning, 2011.

KERCKHOFF, Marcia Telesca. A atuação e o discurso do professor na tutoria online no ensino superior. Tese de doutorado. (Programa Interdisciplinar de Pós-Graduação em Linguística Aplicada), Universidade Federal do Rio 
de Janeiro, Rio de Janeiro, 2014. Disponível em < http:/ / www.letras.ufrj.br/linguisticaaplicada/site/teses/ 2014-marciatelesca.pdf $>$. Acesso em 09 de outubro de 2015.

$\mathrm{KOCH}$, Ingedore. A inter-ação pela linguagem. 10 ed. São Paulo: Contexto, 2006.

KOZINETS, Robert. Netnografia: realizando pesquisa etnográfica online. Porto Alegre: Penso, 2014.

MADALENA, Emanuel Verdade da. Netiqueta - as regras sociais de comportamento e comunicação na internet. Dissertação de mestrado $\left(2^{\circ}\right.$ Ciclo de Estudos em Ciências da Comunicação - Estudos de Média e Jornalismo), Faculdade de Letras - Universidade do Porto, Portugal, 2013. Disponível em < https://sigarra.up.pt/flup/pt/ publs_pesquisa.FormView?p_id=72155 >. Acesso em 20 de dezembro de 2015.

MARCUSCHI, Luiz Antônio. Da fala para a escrita: atividades de retextualização. São Paulo: Cortez, 2001.

MOITA, Filomena. Game on: jogos eletrônicos na escola e na vida da geração @. Campinas-SP: Editora Alínea, 2007.

MOORE, Michael; KEARSLEY, Greg. Educação a distância: uma visão integrada. São Paulo: Thomson Learning, 2007.

MORAN, José Manuel. A educação que desejamos: novos desafios e como chegar lá. Campinas-SP: Papirus, 2007. 
OLIVEIRA, Daniela Motta de. Políticas de formação continuada de professores. In: OLIVEIRA, Daniela Motta de. Formação continuada de professores: contribuições para o debate. Juiz de Fora: Editora UFJF, 2012.

PALLOFF, Rena M.; PRATT, Keith. O instrutor online: estratégias para a excelência profissional. Porto Alegre: Penso, 2013.

PETERS, Otto. Didática do ensino a distância: experiências e estágio da discussão numa visão internacional. São Leopoldo-RS: Editora UNISINOS, 2006.

PRADO, Maria Elisabette Brisola Brito; ALMEIDA, Maria Elizabeth Bianconcini de. Estratégias em educação a distância: a plasticidade na prática pedagógica do professor. In: VALENTE, José Armando; ALMEIDA, Maria Elizabeth Bianconcini de (orgs.). Formação de educadores a distância e integração de mídias. São Paulo: Avercamp, 2007.

RABELLO, Márcia Rodrigues. Interações sociais no ambiente virtual de aprendizagem: análise da linguagem de feedbacks. Dissertação de mestrado (Mestrado em Educação), Universidade Passo Fundo, Rio Grande do Sul, 2011.

ROCHA, Paula Jung; MONTARDO, Sandra Portella. Netnografia: incursões metodológicas na cibercultura. In: E-compós - Revista da Associação Nacional dos Programas de Pós-Graduação em Comunicação, dez, 2005. Disponível em < http://compos.org.br/seer/index. 
php/e-compos/article/viewFile/55/55 > Acesso em 20 de fevereiro de 2015.

SHEPHERD, Tania Granja; SALIÉS, Tania Gastão. Linguística da internet. São Paulo: Contexto, 2013.

SILVA, Ivanderson Pereira da; LESSA, Rose Karla Cordeiro; MERCADO, Luís Paulo Leopoldo. Mediação pedagógica em fóruns de discussão no contexto da experiência do estágio de docência online. In: Revista EDaPECI São Cristóvão (SE), v.15. n. 1, p. 30-56, jan. /abr. 2015. Disponível em <http://www.seer.ufs.br/index.php/ edapeci/article/view/3076/pdf>. Acesso em 07 de outubro de 2015. 